\title{
Vocational Adjustment Level of Employees at Irbid University College
}

\author{
Mufadi Al-Momani ${ }^{1}$ \\ ${ }^{1}$ Al-Balqa Applied University, Jordan \\ Correspondence: Mufadi Al-Momani, Al-Balqa Applied University, Jordan. Tel: 962-79-518-6758. E-mail: \\ mufadi@bau.edu.jo
}

Received: February 28, 2018

Accepted: March 30, 2018

Online Published: May 29, 2018

doi:10.5539/ies.v11n6p164

URL: https://doi.org/10.5539/ies.v11n6p164

\begin{abstract}
The current study aimed to detect the vocational adjustment level of employees at Irbid University College, and to achieve this goal the study tool; vocational adjustment measurement was developed by the researcher and implemented, after confirming its constancy, stability, and truthfulness, which consist of (36) paragraphs spreading over four dimensions (The reality of work climate, physical income, relationship with co-workers, and relationship with management) on the study populations which consist of (141) employees, and the respondents of (121) of those were subject to the statistical analysis. The study results showed the overall vocational adjustment level of employees at Irbid University College to be medium, where all the dimensions came at medium level, in the order (The reality of working climate, physical income, relationship with coworkers, and relationship with management). The study results also showed the existence of statistically significant difference at level $(\alpha=0.05)$ between the two arithmetic means of study sample member estimates on all dimensions of vocational adjustment measurement, and on it all together, due to the sex variable, and in favor of males, and the existence of statistically significant difference at level $(\alpha=0.05)$ between the two arithmetic means of study sample member estimates on all dimensions of vocational adjustment measurement, and on it all together, due to the years of experience variable, and in favor of employees with years of experience of (10 years or more), and also the non- existence of statistically significant difference at level $(\alpha=0.05)$ between the two arithmetic means of study sample member estimates on all dimensions of vocational adjustment measurement, and on it all together, due to the interaction between the two variables of sex and years of experience.
\end{abstract}

Keywords: vocational adjustment level, Irbid University College employees, reality of work climate, physical income, relationship with co-workers, relationship with management

\section{Introduction}

The vocational adjustment considers one of the important and essential matters and issues for employees to perform their duties, at the best way possible, due to its association with their job success, and their adaptation to the work environment socially, physically, and psychologically to achieve the greatest balancing level. The vocational adjustment also reflects employees' job satisfaction, environmental components, and their relationship with co-workers (Fahjan, 2010). It is a state of agreement and compatibility between employees and their job, where it make them satisfied with their work, and others are satisfied by them (Awad, 1988), which is a collection of psychological, physiological, and environmental conditions that surrounded employees' relationship with their co-workers and superiors, and align with their personalities which make them say honestly we are happy with our job. Therefore, the vocational adjustment considers one of the topics that should remain the subject of study and research; from time to time, because what pleases the individuals right now may not please them in the future, in addition to the influence of individuals' adjustment with the changes in their life (Abd-Alal, 2006).

Researcher finds that in order to rise and advance the level of college and university students, and provide them with the psychological, educational, and social services, they must pay attention to the academic and administrative staffs and employees who own one of the most difficult careers that require psychological, mental, and neural effort, high flexibility level, and balanced, well-matched, and adapted personality psychologically, vocationally, and socially, with people around them in the educational, academicals, and social environment. The employees always need to fit in and adjust with the new conditions, businesses, and environments, in addition to the great benefits of institution, in case employees were put in the right place, which will increase employees' 
productivity and improve their adjustment with the job, their relationships with themselves, with co-workers, and managers (Taha, 1980).

The interest of institutions, to establish clubs, promote sports activities, hold concerts, excursions, and trips, and the different social and recreational activities, also help to improve the required relationship of employees with their co-workers and increase their adjustment and alignment with them (Taha, 1992), and the compatible employees who adjust well with their job, usually have a good relationship with the regime and administrative bodies of institution, but workers who can't find the psychological and vocational satisfaction, they lead the striking list inside the enterprise, therefore the organization has to find and examine the real reasons of the bad relationship between the workers and the institution, and its administrative bodies, and tries hard to remove it and dispose it (Taha, 1992), to achieve the vocational, psychological, and social compatibility and adjustment.

\section{Study problems}

BAU represented by its management body seeks to achieve its administrative and technical objectives and tasks, through paying attention to the vocational adjustment level between employees, which consider an indicator for their success to perform the various duties and tasks. There are many studies that indicate the positive relationship between the vocational adjustment and employees' practices of their functional tasks to the fullest way. Therefore, this study came to detect the vocational adjustment level of employees at Irbid University College, as one of the BAU colleges, by answering the following two questions of the study:

1) The first question which stated: What is the vocational adjustment level of employees at Irbid University College?

2) The second question which stated: Are there any existence of statistically significant difference at level $(\alpha=$ 0.05 ) between the arithmetic means of study sample member estimates on all dimensions of vocational adjustment measurement, and on it all together, due to the interaction between the two variables sex and years of experience?

\section{Study Importance}

The importance of this study stems from its concentration on the concept of vocational adjustment, which considers one of the most important requirements of any profession, therefore if the individuals found a profession that align with their personality characteristics, this would lead them to be satisfy about their jobs and in adjustment with their professions. The researcher, as the dean of students at the college didn't find any study that deal with the concept of vocational adjustment among the employees of Irbid University College, and the importance of this applied study comes through the results of it, which can direct the authorities and decision makers to increase the vocational compatibilities and adjustments of their employees.

\section{Previous Studies}

The study of Naisse (2017) aimed to detect the harassment sensibility level at a sample of employees in the Damascus Directorate of Education, and identify their vocational adjustment level, examine the relationship between harassment sensibility and the vocational adjustment of those employees, and also identify the significance level of differences in the answers of study sample members on the harassment sensibility and vocational adjustment measurements, according to the study variables (sex \& marital status). The study results showed that the level of harassment sensibility and vocational adjustment of employees at the Damascus Directorate of Education was at medium level and also the existence of statistically significant negative correlation relationship between the harassment sensibility and vocational adjustment. It also found statistically significant differences in the average (arithmetic mean) of harassment sensibility, attributed to the sex variable, and in favor of male workers, and found statistically significant differences in the average measurement of harassment sensibility, due to the marital status variable, and in favor of the unmarried workers; and finally the study found statistically significant differences in the arithmetic means of the study sample member answers, on the vocational adjustment measurement, due to the sex variable, and in favor of female workers, while the results didn't show any statistically significant differences in the arithmetic means of study sample member answers, on the vocational adjustment measurement, according to the marital status variable.

While the fields study of Sbeara, Khealeh, and Nasser (2014) aimed to reveal the psychological pressures and its relationship with the vocational adjustment, among a sample of basic level education male and female teachers in the province of Al Ladhiqiyah. The researchers arrived to the following results: there is a correlation relationship between the psychological pressures and vocational adjustment of study sample members, and there are differences on the measurements of psychological pressures and vocational adjustment, according to the sex variable, and there are also differences between the sample members on the measurements of psychological 
pressure and vocational adjustment, according to the experience variable.

But the study of Hijazi (2013) aimed to reveal the level of self-effectiveness, vocational adjustment level, and performance quality at the female teachers of resource rooms in the West Bank government schools, and aimed to determines the relationship between each of the self-effectiveness, vocational adjustment level, and performance quality, and the three measurements self-effectiveness, vocational adjustment level, and performance quality. The results showed that the level of self-effectiveness is more than the default level $(80 \%)$, but the vocational adjustment and performance quality level is less than the default level of $(80 \%)$. It showed the existence of statistically significant correlation relationship between the self-effectiveness measurement dimensions, and the vocational adjustment measurement dimensions, except the social adjustment and the performance quality measurement, and also the existence of statistically significant differences between the arithmetic means of resource room teachers' degrees in the West Bank schools; the high self-effectiveness and the low self-effectiveness on the measurements of vocational adjustment and performance quality.

While Al-Shafi'i (2008) held a study to reveal the nature of relationship between the vocational adjustment, among the employees of government hospitals in the Gaza Province and their personal characteristics, and to identify the differences in the vocational adjustment and their personal characteristics, according to the variables (sex, qualification, and years of experience). The results showed a positive correlation relationship between the vocational adjustment, among the study sample members and their personal characteristics, and the non-existence of statistically significant differences in the vocational adjustment, due to the variables (sex, qualification, and years of experience).

But the AL-Muhana (2002) held a study that aimed to reveal the difference in the vocational adjustment and the achievement motivation, according to the variables of (age, years of experience, and salary). The results showed that majority of employees feel good and satisfy about accomplishing the tasks and duties assigned to them, and the majority of them feel that their work provides them with good experience, which in turn indicates their job adjustment, and the more functional expertise they have the more adjustment they will be with their job. It's also clear that employees' dissatisfaction about their jobs is related to the morale incentives, rewards, and low salaries.

Where Al-Shahri (2000) did a study to deduct the relationship between the vocational adjustment and some personality characteristics, at the employees' of both public and private sectors, in the area of health services, and examine the differences in vocational adjustment and the personal characteristics (emotional balance, responsibility, and motivation for achievement), according to the variables (salary, relationship with co-workers, adaptation to work environment, working hours, holidays, working hours, and management). The results showed a correlation relationship between the vocational adjustment and some personal characteristics of public and private sectors' employees, and the existence of statistically significant differences at the overall degree of vocational adjustment between the public and private sectors' employees, and in favor of public sector employees, and also the existence of statistically significant differences between the employees of public and private sectors, in the emotional balance, and in favor of public sector employees.

\section{Study Procedures}

\subsection{Conventional and Procedural Definitions}

- Adjustment: psychologically is a process that refers to human's understanding of their feelings, behaviors, and thoughts, at level that allow to draw a strategy to face and cope with the pressures, demands, and requirements of everyday life (Allen, 1990).

- Vocational adjustment: conventionally is a continuous dynamic process of individuals interactivities with others, and ensure the total understanding of self and vocational maturity and readiness, which leads to the synchronization of authorities, co-workers, and job conditions to achieve the efficiency, satisfaction, and success (Al-Shamri, 2000), and the researcher defines it procedurally as the total grade that employees obtained at Irbid University College, after their responses to the vocational adjustment measurement developed by the researcher, which consist of (36) paragraphs.

\subsection{Study Population \& Sample:}

The study population consist of all (140) male and female employees at Irbid University College, where the researcher, as the dean of students at the college distributed the study tool on them, retrieve (121) of those questionnaires, (113) were valid for statistical analysis and the remaining (8) were excluded, due to the response standardization or for incomplete information. Table 1 shows the distribution of study sample members, according to their sex and years of experience variables. 
Table 1. Distribution of study sample members, according to their sex and years of experience variables

\begin{tabular}{lcccc}
\hline \multirow{2}{*}{ Sex } & & \multicolumn{2}{c}{ Years of experience } & \multirow{2}{*}{ Total } \\
\cline { 3 - 4 } & & Less than 10 Yrs & From 10 yrs and more & \\
\hline Male & The Number & 32 & 30 & 62 \\
\hline & Percentage & $28.3 \%$ & $26.5 \%$ & $54.9 \%$ \\
\hline Female & The Number & 34 & 17 & 51 \\
\hline & Percentage & $30.1 \%$ & $15.0 \%$ & $45.1 \%$ \\
\hline Total & The Number & 66 & 47 & 113 \\
\hline & Percentage & $58.4 \%$ & $41.6 \%$ & $100.0 \%$ \\
\hline
\end{tabular}

\subsection{Study Tool}

The researcher through referring back to the theoretical literature related to psychological adjustment, and for the purposes of achieving goals of the present study, developed the study tool which consist; in its final form from (36) paragraphs spreads over four dimensions: (the reality of work climate) and included (9) paragraphs, (relationship with management) and included (9) paragraphs, (the relationship with co-workers) and included (8) paragraphs, and the dimension of (physical income) and included (10) paragraphs.

\subsection{Tool Sincerity \& Truthfulness}

To verify the genuineness and truthfulness of study tool that contain (40) paragraphs; in its initial form (10 paragraphs for each dimension), the researcher presented it on (11) experience and competence arbitrators, four of those in the field of vocational education, three in the field of educational psychology, two in the assessment and evaluation, and two arbitrators in the field of Arabic language, and after taking the opinions of arbitrators, the study tool became (36) paragraphs, where five paragraphs were deleted (two from the first dimension, one paragraph from each of the second, third, and fourth dimensions), and added two paragraphs (one paragraph was added to the first dimension and another paragraph on the fourth dimension), and combine two paragraphs in one in the third dimension. The researcher also verify the sincerity of study tool design, through calculating the (Corrected Item-Total Correlation) due to the correlation of each paragraph in it with the dimension each paragraph associated with the tool as a whole, where its values ranged between $(0.37)$ and $(0.71)$, and all of it are acceptable for the purposes of current study.

\subsection{Tool Constancy \& Stability}

To verify the consistency of study tool; researcher estimated the internal consistency, using Cronbach alpha coefficient, for each dimension of the measurement where its values ranged between (0.81) and (0.93), and for the measurement as a whole (0.92), and all of it are acceptable for the purposes of current study.

\subsection{Statistical Standard and Measurement}

To identify the level of vocational adjustment of employees at Irbid University College, researcher used the statistical criterion indicated in Table 2 below:

Table 2. Statistical measurement used in the current study, to identify the vocational adjustment level of employees at Irbid University College

\subsection{Study Variables}

\begin{tabular}{cc}
\hline Arithmetic mean & Level \\
\hline From $1.00-$ less than 1.80 & Very low \\
From $1.80-$ less than 2.60 & Low \\
From $2.60-$ less than 3.40 & Medium \\
From $3.40-$ less than 4.20 & High \\
From 4.20-5.00 & Very high \\
\hline
\end{tabular}

The study included the following independent variables, sex: which has two categories (male, female), and years of experience, which has two levels (less than 10 years, 10 years and more), and also included the dependent variable represented in vocational adjustment, among employees of Irbid University College; as a whole, represented in the arithmetic means of study sample members' estimates on the paragraphs of vocational adjustment among employees of Irbid University College, and dimensions of vocational adjustment among employees of Irbid University College, represented by the arithmetic mean of the study sample members' 
estimates on the paragraphs of each dimension of the tool (the reality of work climate, the relationship with management, the relationship with co-workers, and the physical income).

\subsection{Statistical Analysis \& Treatments}

To answer the first question, the arithmetic means and standard deviations have been used to identify the vocational adjustment level of employees at Irbid University College.

To answer the second question, the arithmetic means and standard deviations were used, according to the variables (sex, years of experience), and (Two way ANOVA) to identify the statistical significance of external differences between the arithmetic means of the study sample members' estimates, on the paragraphs of vocational adjustment measurement, as a whole. The arithmetic means and standard deviations were also used, according to the variables (sex, years of experience), and (Two way ANOVA) to identify the statistical significance of external differences between the arithmetic means of the study sample members' estimates, on each dimension of vocational adjustment measurement.

\subsection{Study Limitations}

The study was limited to the employees of Irbid University College, who were registers at the human resources department, in the first semester of the academic year (2017/2018), and also were limited to the four dimensions (The reality of working climate, physical income, relationship with co-workers, and relationship with management).

\section{Results Display and Discussion}

The results of first question which stated: "What is the vocational adjustment level of employees at Irbid University College?", and to answer this question; the standard deviations and arithmetic means were calculated for the study sample members' estimates on the paragraphs of vocational adjustment measurement, as a whole, and each dimensions of its, as shown in Table 3 below:

Table 3. The standard deviations and arithmetic means for the study sample members' estimates on the paragraphs of vocational adjustment measurement, as a whole, and each dimensions of its, in a descending order according to the arithmetic means

\begin{tabular}{|c|c|c|c|c|c|}
\hline $\begin{array}{c}\text { Dimension } \\
\text { number }\end{array}$ & Dimension & Arithmetic means* & STDEV & Rank & Level \\
\hline 1 & Work climate reality & 3.47 & 1.13 & 1 & High \\
\hline 4 & Physical income & 3.35 & 0.90 & 2 & Medium \\
\hline 3 & Relationship with co-workers & 3.33 & 1.09 & 3 & Medium \\
\hline \multirow[t]{2}{*}{2} & Relationship with management & 3.09 & 0.83 & 4 & Medium \\
\hline & Vocational adjustment as a whole & 3.31 & 0.90 & & Medium \\
\hline
\end{tabular}

Low degree (1) and high degree (5).

It notices from Table 3 that vocational adjustment level as a whole, of employees at Irbid University College is (medium) with arithmetic mean of (3.31) and standard deviation of $(0.90)$, where the first dimension (the reality of work climate) came first with an arithmetic mean of (3.47) at level (high), followed by the fourth dimension (physical income) with an arithmetic mean of (3.35) at level (medium), while the third dimension (the relationship with co-workers) came third with an arithmetic mean of (3.33) at level (medium), and finally the second dimension (relationship with management) came in the fourth and last place with an arithmetic mean of (3.09) at level (medium) too. The researcher attribute this result to the fact that most employees at the university, have been in their current jobs, and in the same department for a long time, and they are doing the same tasks and duties, therefore workers become more adapted to their jobs, get used to it, and also become part of their lives, despite some physical difficulties and family obligations. In regard to the work climate, which got the first rank, it considers a comfortable climate for workers, where there is no pressure in the volume of work and no difficulty in it, and also the number of employees is relatively large compared with the size of work, which leads to spreading the works and duties. The employees also become; as a result of their experiences, familiar with getting rid and overcoming the difficulties that face them, besides the work place is relatively close to their residences, which provide an atmosphere of psychological comfort among workers. In regard to the second dimension (physical income), the result is logical according to the researcher, where employees' salaries at the universities are relatively higher than most of the other jobs or careers, whether it was in the private or public sectors, therefore they will feel 
good and satisfy about their salaries when they compare it with salaries of others, but as related to the third dimension (the relationship with co-workers), its connected with the nature of individuals, and as time passes some of them build social friendships and relationships with other co-workers, and at the same time, they may have taken a negative impression from someone else, as a result of certain situation happened between them, or disputes in the work place. Finally, the result is logical for the fourth dimension (relationship with management), where the relationship is govern by regulations and instructions, and isn't govern by personal or social aspects, and with the time, the employees must be subject to punishment or reprimand by the management, as a result of making mistakes at work, or due to not getting the incentives or positions they desire, which make them in contradiction and disagreement with the management, and also some employees may mix between the personal and official matters, which harm the relationship between workers and management.

The results of second question which stated: Are there any existence of statistically significant difference at level $(\alpha=0.05)$ between the arithmetic means of study sample member estimates on all dimensions of vocational adjustment measurement, and on it all together, due to the two variables sex and years of experience, and the interaction between them?, and to answer this question; the standard deviations and arithmetic means were calculated for the study sample members' estimates on the paragraphs of vocational adjustment measurement, as a whole, according to the (sex, and years of experience) variables, as shown in Table 4 below:

Table 4. Standard deviations and arithmetic means were calculated for the study sample members' estimates on the paragraphs of vocational adjustment measurement, as a whole, according to (sex, and years of experience) variables

\begin{tabular}{cccc}
\hline Sex & Years of experience & Arithmetic means & STDEV \\
\hline \multirow{4}{*}{ Male } & Less than 10 yrs & 3.31 & 0.85 \\
& From 10 yrs and more & 3.86 & 0.56 \\
& Overall & 3.58 & 0.77 \\
\hline \multirow{4}{*}{ Female } & Less than 10 yrs & 2.78 & 0.92 \\
& From 10 yrs and more & 3.40 & 0.85 \\
& Overall & 2.98 & 0.94 \\
\multirow{2}{*}{ Overall } & Less than 10 yrs & 3.04 & 0.92 \\
& From 10 yrs and more & 3.69 & 0.71 \\
& Overall & 3.31 & 0.90 \\
\hline
\end{tabular}

It notices from Table 4, the existence of external differences between the arithmetic means of the study sample members' estimates on the paragraphs of vocational adjustment measurement as a whole, according to (sex, years of experience) variables, and to determine the statistical significance of these external differences, (Two way ANOVA) analysis were implemented, and it shows through Table 5 below:

Table 5. Two way ANOVA analysis for the arithmetic means of study sample members' estimates on the paragraphs of vocational adjustment measurement as a whole, according to (sex, years of experience) variables

\begin{tabular}{lccccc}
\hline Variable & SS & DF & MS & F-value & Sig \\
\hline Sex & 6.503 & 1 & 6.503 & $* 9.935$ & 0.002 \\
Years of experience & 8.847 & 1 & 8.847 & $* 13.515$ & 0.000 \\
Sex X years of experience & 0.031 & 1 & 0.031 & 0.048 & 0.827 \\
Errors & 71.354 & 109 & 0.655 & & \\
\hline Modified Total & 90.101 & 112 & & & \\
\hline
\end{tabular}

* Statistically significant at the level $(\alpha=0.05)$.

It notices from Table 5 the following:

- The statistical significance value for the sex variable amounted to (0.002), which is lower than the statistical significance level of $(\alpha=0.05)$, and indicate the existence of statistically significant difference at level $(\alpha=$ 0.05 ) between the two arithmetic means of the study sample members estimates on the paragraphs of vocational adjustment measurement as a whole, due to the sex variable, and from the table of arithmetic means, it shows the statistically significant difference in favor of males. The researcher attribute this result to 
the fact that male workers at the most, are working in jobs that suited to their qualifications and experience, such as accounting, maintenance, services, and security, which make them more in line with their jobs, since they are within their specialty, while most female workers, are in management positions that aren't related to their specialties, besides the most concern of male workers is their job, and not linked to other works, but females are most likely were connected to their family and household duties, which distract their concentration, due to the busy thought about these duties, and the things associated with it, such as caring for the children, feeding them, and teaching them, and other duties.

- The statistical significance value for the years of experience variable amounted to $(0.000)$, which is lower than the statistical significance level of $(\alpha=0.05)$, and indicate the existence of statistically significant difference at level $(\alpha=0.05)$ between the two arithmetic means of the study sample members estimates on the paragraphs of vocational adjustment measurement as a whole, due to the years of experience variable, and from the table of arithmetic means, it shows the statistically significant difference in favor of employees with (10 yrs or more). The researcher sees this as the normal estate that must exist in any job or position, and as the time passes individuals become more adjusted, aligned, and well adapted with their works, where they becomes more knowledgeable and professional in their jobs, more capable of overcoming the difficulties, and finding the ways that facilitate their works and helping them to arrive to work advantages and earnings, therefore as their experiences increase, they become increasingly adjusted with their works, beside with their long experiences they would have looked over the duties of their co-workers in the other positions and felt the amount of advantages they enjoy in their jobs, but others don't get it.

- The statistical significance value for the interactivity between the two variables of sex and years of experience amounted to (0.827), which is higher than the statistical significance level of $(\alpha=0.05)$, and indicate the non-existence of statistically significant difference at level $(\alpha=0.05)$ between the two arithmetic means of the study sample members estimates on the paragraphs of vocational adjustment measurement as a whole, due to the interactivity between the two variables of sex and years of experience, and Table 6 calculated the arithmetic means and standard deviations of the study sample members' estimates on each dimension of vocational adjustment measurement, according to the (sex, years of experience) variables.

Table 6. The arithmetic means and standard deviations of the study sample members' estimates on each dimension of vocational adjustment measurement, according to the (sex, years of experience) variables

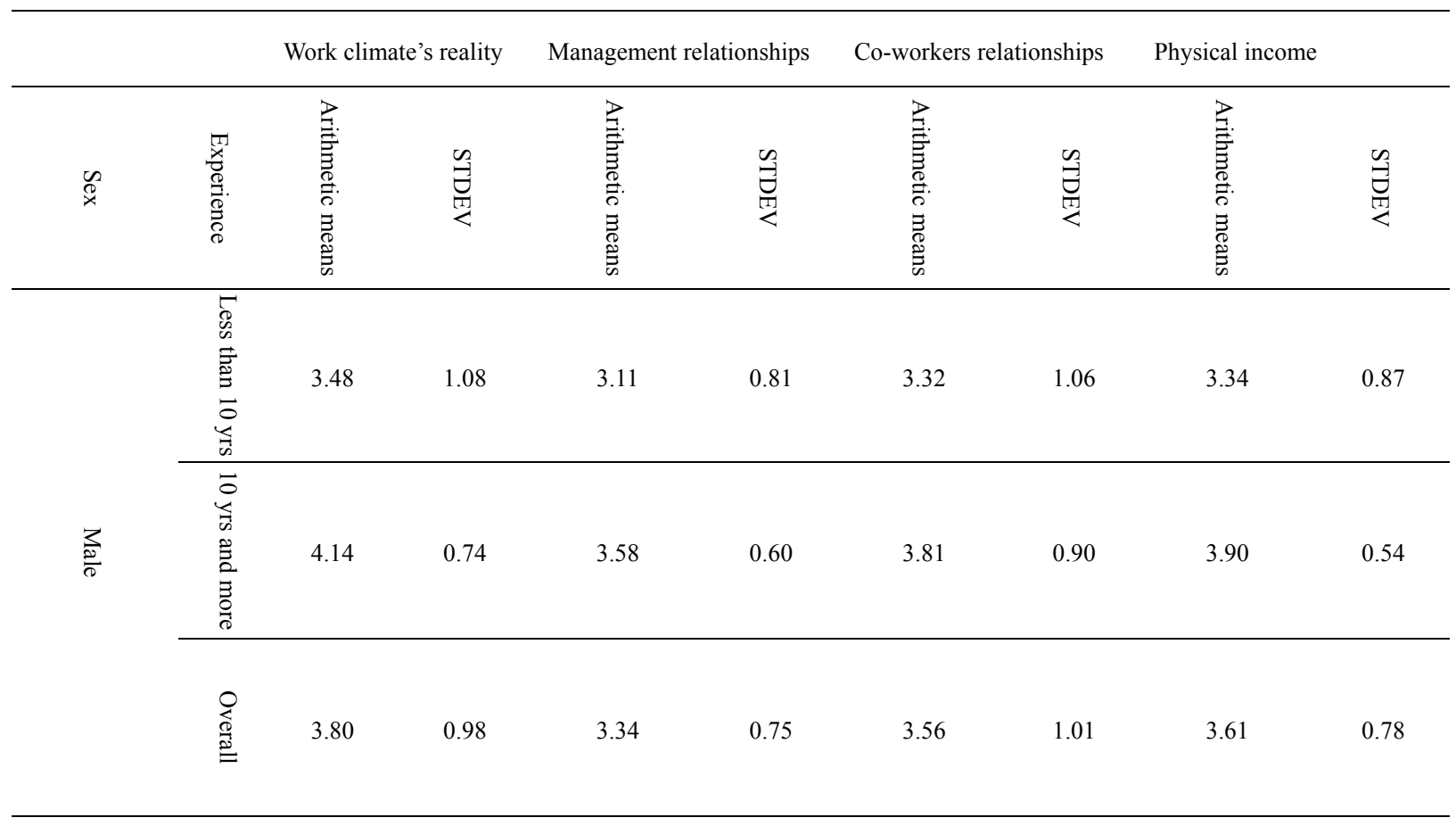




\begin{tabular}{|c|c|c|c|c|c|c|c|c|c|}
\hline \multirow{3}{*}{$\begin{array}{l}\frac{T}{0} \\
\stackrel{0}{0} \\
\stackrel{0}{0}\end{array}$} & 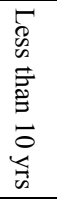 & 2.85 & 1.11 & 2.65 & 0.80 & 2.78 & 1.10 & 2.83 & 1.00 \\
\hline & $\begin{array}{l}\overrightarrow{0} \\
\vdots \\
0 \\
0 \\
0 \\
0 \\
\Xi \\
0 \\
0 \\
0\end{array}$ & 3.48 & 1.19 & 3.07 & 0.88 & 3.57 & 1.06 & 3.47 & 0.69 \\
\hline & $\begin{array}{l}0 \\
\stackrel{0}{0} \\
\stackrel{0}{\mathscr{P}} \\
=\end{array}$ & 3.06 & 1.17 & 2.79 & 0.84 & 3.04 & 1.14 & 3.05 & 0.95 \\
\hline \multirow{3}{*}{ 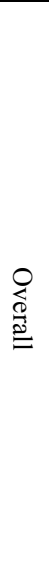 } & 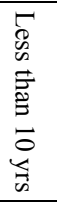 & 3.15 & 1.13 & 2.88 & 0.83 & 3.04 & 1.10 & 3.08 & 0.97 \\
\hline & 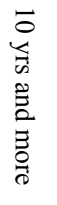 & 3.90 & 0.97 & 3.39 & 0.75 & 3.73 & 0.96 & 3.74 & 0.63 \\
\hline & 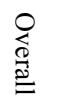 & 3.47 & 1.13 & 3.09 & 0.83 & 3.33 & 1.09 & 3.35 & 0.90 \\
\hline
\end{tabular}

It notices from Table 6, the existence of external differences between the arithmetic means of the study sample members' estimates on each dimension of the vocational adjustment measurement, according to (sex, years of experience) variables, and to determine the statistical significance of these external differences, (Two way ANOVA) analysis were implemented, and it shows through Table 7 below:

Table 7. (Two way ANOVA) analysis for the arithmetic means of the study sample members' estimates on each dimension of the vocational adjustment measurement, according to (sex, years of experience) variables

\begin{tabular}{lcccccc}
\hline Variance source & Dimension & SS & DF & MS & F-value & Sig \\
\hline \multirow{2}{*}{ Sex } & Work climate & 10.773 & 1 & 10.773 & $* 10.149$ & 0.002 \\
Hotelling's trace $=0.155$ & Relationship with management & 6.242 & 1 & 6.242 & $* 10.582$ & 0.002 \\
Statistical significant=*0.004 & Relationship with co-workers & 3.940 & 1 & 3.940 & 3.707 & 0.057 \\
& Physical income & 5.713 & 1 & 5.713 & $* 8.596$ & 0.004 \\
\hline \multirow{2}{*}{ Years of experience } & Work climate & 11.042 & 1 & 11.042 & $* 10.403$ & 0.002 \\
Hotelling's trace=0.134 & Relationship with management & 5.047 & 1 & 5.047 & $* 8.556$ & 0.004 \\
Statistical significant=*0.009 & Relationship with co-workers & 10.893 & 1 & 10.893 & $* 10.250$ & 0.002 \\
& Physical income & 9.333 & 1 & 9.333 & $* 14.044$ & 0.000 \\
\hline \multirow{2}{*}{ Sex X years of experience } & Work climate & 0.006 & 1 & 0.006 & 0.006 & 0.939 \\
Wilks' Lambda=0.978 & Relationship with management & 0.015 & 1 & 0.015 & 0.026 & 0.873 \\
Statistical significant $=* 0.676$ & Relationship with co-workers & 0.581 & 1 & 0.581 & 0.547 & 0.461 \\
& Physical income & 0.044 & 1 & 0.044 & 0.067 & 0.797 \\
\hline \multirow{2}{*}{ Errors } & Work climate & 115.703 & 109 & 1.061 & & \\
& Relationship with management & 64.298 & 109 & 0.590 & & \\
& Relationship with co-workers & 115.839 & 109 & 1.063 & & \\
& Physical income & 72.437 & 109 & 0.665 & & \\
\hline
\end{tabular}




\begin{tabular}{cccc}
\hline & Work climate & 142.285 & 112 \\
Modified Total & Relationship with management & 78.038 & 112 \\
& Relationship with co-workers & 134.142 & 112 \\
& Physical income & 90.760 & 112 \\
\hline
\end{tabular}

* Statistically significant at the level $(\alpha=0.05)$.

It notices the following from Table 7:

- The statistical significance value for the sex variable, and for all dimension except for the (relationship with co-workers) dimension is lower than the statistical significance level of $(\alpha=0.05)$, and indicate the existence of statistically significant difference at level $(\alpha=0.05)$ between the two arithmetic means of the study sample members estimates on all dimensions, due to the sex variable, and from the table of arithmetic means, Table 6 , it shows the statistically significant difference in favor of males. The researcher attribute this result to the fact that male workers are more acceptable to the reality of work climate, because many of them help females in the other jobs and duties, and also most of them are working in jobs well-matched with their specialties or experiences. In regard to the relationship with management, the male workers are more brave in dealing with the management, and building a relationship with it, taking into account that university management mostly male in nature, while female workers are more fearful and cautious in dealing with the management, and in relation to physical income, the male workers feel that physical returns and salaries of their job, are suitable for the size and nature of work, but females may see the income they receive isn't equivalent to leaving their children and their homes.

- The statistical significance value for the years of experience variable, and for all the dimensions of vocational adjustment measurement are lower than the statistical significance level of $(\alpha=0.05)$, and indicate the existence of statistically significant difference at level $(\alpha=0.05)$ between the two arithmetic means of the study sample members estimates on all dimensions, due to the years of experience variable, and from the table of arithmetic means, Table 6 , it shows the statistically significant difference in favor of employees with (10 or more) years of experience. This result, according to the researcher opinion returns to the more experience workers who become more acceptable to the work climate, because they got used to it, and adjusted, aligned, and well adapted to their work climates, and they become more capable of overcoming the difficulties that face them in the work place, and in regard to the (relationship with co-workers) dimension, due to the very long period those workers spent in the same place, they developed social relationships and friendships with their co-workers, and they felt as one family, where they share the joys and sorrows, but in regard to (the relationship with management) dimension, where with the long time period, the workers gained experience in dealing with the management, beside those who work in the management are originally from the university workers, and who have been in a relationship with them for a long time, and also the most experienced workers had moved to managerial positions higher than their less experienced co-workers, therefore they became closer to the management; due to nature of work. Finally, in regards to the fourth dimension (physical income), the most experienced employees received annual increases in salaries higher than their less experienced co-workers, and their pays increased, therefore they become more compatible and more adjustable with their work, due to their satisfaction with the income amount, and their feeling satisfy about the physical returns and salaries they get.

- The statistical significance value for the interactivity between the two variables of sex and years of experience, and for all dimensions of vocational adjustment measurement are higher than the statistical significance level of $(\alpha=0.05)$, and indicate the non-existence of statistically significant difference at level ( $\alpha$ $=0.05$ ) between the two arithmetic means of the study sample members estimates on all dimensions of vocational adjustment measurement, due to the interactivity between the two variables of sex and years of experience

\section{Recommendations}

The researcher as the dean of students at the college, and according to the study results recommend to increase the interest and concern about the vocational adjustment level of employees at Irbid University College by holding training courses, sessions, and workshops, which will help to promote employees' vocational adjustments. The researcher also recommend to perform further studies that will deal with revealing a relationship between the vocational adjustment of employees at Irbid University College, and other personal variables, such as emotional sobriety, self-esteem, self-respect, and other variables. 


\section{References}

Al-Shafi' 'i, M. A. (2002). Vocational adjustment of nurses working in government hospitals and its relation to the personal characteristics (Unpublished master thesis). School of education, Graduate studies, Islamic University, Gaza, Palestine.

Al-Shahri, A. A. (2000). The relationship between vocational adjustment and some personality characteristics of the staff at government and private sectors in the field of health services in Riyadh (Unpublished master thesis). The Arabic Naif University for Security Sciences, Riyadh, Saudi Arabia.

Alshammari, K. A. S. (2000). Self-consciousness and its relationship with vocational adjustment (Unpublished master thesis). Baghdad University, Faculty of arts, Baghdad, Iraq.

Awad, A. M. (1988). The industrial and Vocational Psychology. Community knowledge and research center, Cairo, Arab Republic of Egypt.

Di Martino, M., Einarsen, S., Hoel, H., Zapf, D., \& Cooper, C. (2003). Bullying and emotional abuse in the workplace. International perspectives in research and practice. New York: Taylor \& Francis.

Fahjan, S. K. (2010). Vocational adjustment and social responsibility, and their relationships with the ego flexibility at the private education teachers (Unpublished master thesis). School of education, Graduate studies, Islamic University, Gaza, Palestine.

Flores, C. (2014). First Generation College Student Financial Literary: Impact of Self-Efficacy and Behavior. DAI-A, Washington State University, Washington, USA.

Hijazi, J. H. (2013). Self-efficacy and its relationship with vocational adjustment and performance quality of teachers at the resource rooms in West Bank public schools. Jordan Magazine for Educational Sciences, 9(4), 419-433.

Hui-fang, L. (2007). The relationships among personality traits, self-efficacy and organizational commitment in fitness center staff (Dissertation of master degree, Spalding University).

Naisse, R. (2017). Feeling harassed and its relationship to the level of vocational adjustment among sample of employees at Damascus Directorate of education. Journal of Educational and Psychological Studies, 11(2), 278-298. https://doi.org/10.24200/jeps.vol11iss2pp278-296

Taha, F. (1980). Personal Psychological obstructions of production, field and theoretical study in vocational adjustment and mental health. Al-kanji library, Cairo, Arab Republic of Egypt.

Taha, F. (1992). Industrial and organizational psychology (7th ed., pp. 55-57). Dar Al Maaref, Cairo, Arab Republic of Egypt.

\section{Copyrights}

Copyright for this article is retained by the author(s), with first publication rights granted to the journal.

This is an open-access article distributed under the terms and conditions of the Creative Commons Attribution license (http://creativecommons.org/licenses/by/4.0/). 